\title{
Immune cell kinetics in the ovine abomasal mucosa following hyperimmunization and challenge with Haemonchus contortus
}

\author{
Nicholas Robinson ${ }^{1}$, David Piedrafita ${ }^{1}$, Kenneth SnibSON $^{2}$, \\ Paul Harrison ${ }^{3}$, Els N. MeEusen ${ }^{1 *}$ \\ ${ }^{1}$ Biotechnology Research Laboratories, School of Biomedical Sciences, Monash University, \\ Clayton, VIC 3800, Australia \\ ${ }^{2}$ Centre for Animal Biotechnology, School of Veterinary Science, The University of Melbourne, Australia \\ ${ }^{3}$ Victorian Bioinformatics Consortium, School of Biomedical Sciences, Monash University, Australia
}

(Received 2 November 2009; accepted 1 February 2010)

\begin{abstract}
Sheep were sensitized by repeated infection with Haemonchus contortus L3, followed by a 12 week rest period, and an abomasal cannula was surgically implanted in all sheep. Seven of the sensitized sheep were subsequently challenged with $50000 \mathrm{H}$. contortus L3 while 4 control sheep were challenged with saline. Biopsy samples were taken using a fibreoptic endoscope on days $0,1,2,3,5,7$ and 28 after challenge and leukocyte subpopulations quantified by (immuno)histology. Differential blood cell counts were performed on the same days. At the end of the trial, sheep showed significantly reduced worm burdens compared to unsensitized control sheep, confirming their resistance status. Both blood and tissue eosinophils, as well as tissue $\gamma \delta \mathrm{TCR}^{+}$cells were rapidly elevated by day 1 post $\mathrm{L} 3$ challenge (pc), peaking at day 3 pc. There was a slight increase in tissue CD4 T cells at day 2 pc, peaking at day 3 pc while no significant changes in CD8 T cells were observed. B cells $\left(C D 45 R^{+}\right)$increased later into challenged tissues with a peak at 5 days pc. All tissue lymphocyte subpopulations as well as tissue and blood eosinophils were reduced by day $7 \mathrm{pc}$ before increasing again at day $28 \mathrm{pc}$, suggesting separate responses to larval and adult antigens. In contrast, globule leukocytes and mucosal mast cells only showed one peak at day $5 \mathrm{pc}$ and $28 \mathrm{pc}$, respectively. Unexpectedly, globule leukocytes correlated significantly with tissue eosinophils but not mucosal mast cells. The results are consistent with an early eosinophil-mediated killing of L3, possibly recruited by IL- 5 produced by $\gamma \delta$ T cells. In contrast to post-mortem studies, abomasal cannulation allowed sequential analysis of both early and late time points in the same animal, providing a more complete picture of cellular interactions at both peripheral and local sites, and their correlation with the different stages of parasite development.
\end{abstract}

nematode / immunity / sheep / eosinophil

\section{INTRODUCTION}

There have been several studies characterizing the cellular changes that occur with primary

\footnotetext{
* Corresponding author: els.meeusen@med.monash. edu.au
}

and challenge nematode infections in both rodent and ruminant models (reviewed in [1,9]). Very few of these studies have investigated the early period of putative larval rejection and most have concentrated on adult stage interaction with the host. Several experiments have however shown that larval rejection can and does occur in both 
Haemonchus contortus and Trichostrongylus colubriformis $[14,15]$, and this may be the predominant mechanism of resistance to gastrointestinal nematodes in large animals [1]. Eosinophils, mast cells and globule leukocytes have all been implicated as effector cells mediating resistance to gastrointestinal nematodes, although their precise role in parasite rejection has not been elucidated.

The kinetics of cellular changes with time of infection and immunity can be informative of what immune mechanisms are operating at different stages and how these may interact. These studies have however been limited due to the large number of animals needed for sequential killing when working with outbred populations. Previous studies have shown that abomasal cannulation is an effective tool for collecting mucosal tissue samples in sheep [12]. Collection of consecutive samples from the same animal can reduce individual variation as well as permit the sequential observation of cell populations that are recruited early during the histotrophic stage of the nematode larvae $[12,19,21]$. In the present study, a surgical technique of inserting an abomasal cannula to take abomasal mucosal biopsy samples was employed to observe changes at the site of $H$. contortus infection in immune sheep. Tissue samples obtained via fibreoptic endoscopy allowed both immunohistological and histological characterization of cellular kinetics at early stages of infection with subsequent enumeration of worm establishment. In addition, this procedure allowed direct correlations between cell populations in the same sheep and revealed significant associations between critical cell subpopulations.

\section{MATERIALS AND METHODS}

\subsection{Animals and experimental design}

Eighteen non-pregnant merino cross breed ewes were used in the experiment. Ewes were pasture reared and acquired from a commercial source at 6 months of age. All sheep were treated initially with the manufacturers recommended dose of ivermectin at $8 \mathrm{~mL} / \mathrm{sheep}$ (Ivomec $8 \mathrm{~g} / \mathrm{L}$, Merial, USA) and housed indoors under nematode free conditions for 1 month before commencement of the experiment. Sheep were randomly allocated to 3 groups (Tab. I). Groups 1 and 2 comprised a total of 11 sheep that were sensitized by oral infection with $5000 \mathrm{~L} 3 \mathrm{H}$. contortus L3 larvae once per week for 12 weeks. The sheep were subsequently drenched with ivermectin, and maintained nematode free for a further 12 weeks. Group 2 ( 7 sheep) was then challenged with $50000 \mathrm{~L} 3 \mathrm{H}$. contortus and group 1 (4 sheep) sham challenged with saline. Group 3 comprised 7 sheep which were housed nematode free for 24 weeks without immunization and then challenged with $50000 \mathrm{H}$. contortus L3 larvae (infection controls). The challenge dose was given just after taking the Day 0 biopsy sample in groups 1 and 2. Sheep in all groups were euthanised at 28 days post challenge (pc) by an intravenous injection of lethabarb (Virbac Pty. Ltd, Australia).

Larvae used for sensitizing and challenging the sheep were ensheathed McMaster strain L3 H. contortus. The experiment was approved by the University of Melbourne School of Veterinary Science Animal Ethics Committee (Australia).

\subsection{Parasitological measurements}

Adult worm counts were performed immediately following euthanasia of the sheep. The abomasum was collected and opened along the greater curvature. The entire abomasal contents were counted for adult worms in a transparent dish over a lightbox.

\subsection{Abomasal cannulation}

The abomasal cannula design used was based on [12] and consisted of a $10 \mathrm{~mL}$ syringe, modified by removing the luer end and placing a circular flange over the syringe. The flange was molded from silastic rubber (Dow Corning, Sydney, Australia) and was approximately $7 \mathrm{~cm}$ diameter. This type of rubber was chosen to limit the possibility of mechanical abrasion of the mucosal surface of the abomasum.

Feed was withheld for $24 \mathrm{~h}$ prior to surgery. After anaesthesia, a ventral midline incision was made to locate and exteriorize the abomasum. A $2-3 \mathrm{~cm}$ purse-string suture (Silk 2-0) was placed midway between the lesser and greater curvature approximately $10 \mathrm{~cm}$ from the pyloric sphincter. This location was chosen to reduce the chance of cannula failure and to minimize the disturbance of the $H$. contortus $\mathrm{L} 3$ tissue niche. A stab incision was made in the centre of the purse-string suture. The cannula and inner flange was placed inside the abomasum through the stab incision and the purse-string suture was tightened and tied off. A further stab incision was made in the abdominal wall 
Table I. Experimental protocol.

\begin{tabular}{lcccc}
\hline Group number $(n)$ & $\begin{array}{c}\text { Weeks of } \\
\text { sensitization* }\end{array}$ & $\begin{array}{c}\text { Challenge* } \\
\text { (Day 0) }\end{array}$ & $\begin{array}{c}\text { Weeks between last } \\
\text { sensitization and challenge }\end{array}$ & $\begin{array}{c}\text { Sampling time points } \\
\text { (days post challenge) }\end{array}$ \\
\hline Group 1 (4) & 12 & - & 12 & $0,1,2,3,5,7,28$ \\
Group 2 (7) & 12 & + & 12 & $0,1,2,3,5,7,28$ \\
Group 3 (7) & 0 & + & - & 28 \\
\hline
\end{tabular}

* Sheep were sensitized by weekly infection with $5000 \mathrm{H}$. contortus L3 and challenged with 50000 L3.

approximately $10-15 \mathrm{~cm}$ from the laparotomy incision on the right paramedian area to enable the cannula to be passed freely through while maintaining the abomasum in an anatomically correct position. An external flange was placed over the external syringe barrel which was then secured in place by the use of an elastrator ring (NASCO Export, Fort Atkinson, WI, USA) and metal bolt that was placed transversely through the syringe to both keep the flange in place and the stopper (a shortened $10 \mathrm{~mL}$ syringe plunger) from externally dislodging. There were no problems with cannula failure during the experiment. The external parts of the cannula did not affect the sheep's ability to ambulate or assume a sternally recumbent position.

Post anaesthetic monitoring was carried out with sheep housed individually for $24 \mathrm{~h}$ and then returned to group housing. Procaine penicillin and benzathine penicillin was administered during the surgical procedure at the manufacturers recommended dose $(1 \mathrm{~mL} /$ $20 \mathrm{~kg}$ bodyweight, Duplocillin, Intervet Ltd, Upper Hutt, New Zealand).

\subsection{Biopsy procedure}

Biopsy specimens were taken from both group 1 (sensitized, saline challenged) and group 2 (sensitized, L3 challenged) sheep using a flexible fibreoptic endoscope (Olympus, Sydney, Australia). The biopsy forceps used through the endoscope biopsy port produced a tissue specimen measuring $2 \times 2 \times 3 \mathrm{~mm}$.

Sheep were restrained in a custom made sling which exposed the ventral region of the sheep's abdomen including the cannula. As in previous studies [12], we found no need for sedation as the sheep appeared relaxed and did not show any signs of pain or discomfort during the procedure. While sheep are restrained in the harness, the cannula stopper was removed and the abomasal contents collected. The endoscope was introduced into the abomasum and the fundic region located which was the furthest distance from the cannula. Due to the design of the biopsy forceps, it was found that the most productive biopsy specimens were taken from the tip of the large abomasal folds of the fundic region. The fibreoptic endoscope allowed sufficient visibility (in color) to differentiate structures within a $3-4 \mathrm{~cm}$ distance from the tip of the scope, and characteristic abomasal folds were readily visible. Four biopsy specimens were taken for each time point. At subsequent time points there was never any evidence of tissue injury from previous biopsy collection, as observed macroscopically by eye or examined histologically for signs of inflammation or regenerative changes. The flexible endoscope also allowed different regions of the abomasum to be sampled and, considering the size of the biopsy relative to the surface area of the abomasums, the probability of resampling the same site is minute.

\subsection{Peripheral blood}

Peripheral venous blood was collected by jugular venipuncture and placed into $5 \mathrm{mmol}$ of ethylenediaminetetraacetic acid (EDTA). Total WBC count was performed by adding $10 \mu \mathrm{L}$ of EDTA treated blood with $190 \mu \mathrm{L}$ Turk's solution ( $1 \%$ glacial acetic acid and $0.01 \%$ gentian violet in distilled $\mathrm{H}_{2} \mathrm{O}$ ). Enumeration of cells was performed using a haemocytometer and results expressed as cells per litre of blood.

Differential white cell counts were performed on peripheral blood (PB) smears stained with Diff Quik (Dade Behring, Inc., IL, USA). For differential cell counts, the differential percentage were multiplied by the total WBC count and results expressed as cells per litre of blood.

\subsection{Histological procedures}

For paraffin sections, tissue samples were placed in $10 \%$ neutral buffered formalin and processed at the University of Melbourne Veterinary Histology Laboratory. Eosinophils and globule leukocytes were differentiated morphologically on haematoxylin and eosin stained sections.

For immunostaining, tissue biopsies were embedded in Optimal Cutting Temperature (OCT) medium 
(TissueTek, Miles Inc., USA), frozen on liquid nitrogen and stored at $-70{ }^{\circ} \mathrm{C}$ until used. Five microns of frozen tissue sections were fixed in $200 \mathrm{~mL} 100 \%$ ethanol with $2 \mathrm{~mL} \mathrm{H}_{2} \mathrm{O}_{2}$ for $10 \mathrm{~min}$ at $4{ }^{\circ} \mathrm{C}$ and stained for cell surface markers using ovine-specific monoclonal antibodies $(\mathrm{mAb})$ as described previously $[2,3]$. Briefly, mAbs were anti-sheep $\operatorname{IgE}$, CD4, CD8, CD45, CD45R, $\gamma \delta$ TCR (86D) and WC1 (T19), a $\gamma \delta$-TCR subset.

To stain for mucosal mast cells, frozen sections were stained with $1 \%$ toluidine blue in a solution of $50 \%$ PBS and $50 \%$ methanol for approximately $30 \mathrm{~s}$.

\subsection{Morphometric analysis}

To maximise the number of cells counted per biopsy in the abomasal mucosa, the entire biopsy was counted using a counting graticule (Leica Microsystems, Wetzlar, Germany) of area $0.2 \mathrm{~mm}^{2}$. This technique was used for both frozen and paraffin sections. Each biopsy was recorded as the mean number of cells per graticule field $( \pm$ SEM).

\subsection{Statistical analysis}

Group comparisons were conducted by comparing group 1 with group 2 at each time point utilizing unpaired student's $t$-test. The linear dependence between 2 variables within the experimental group 2 was calculated using the Pearson product-moment correlation coefficient $(r) . p<0.05$ was considered significant.

\section{RESULTS}

\subsection{Changes in peripheral blood WBC after challenge}

Analysis of PB samples taken on days -24 and day 0 before challenge show that both group 2 (L3 challenged) and group 1 (sham challenged) did not significantly differ for any parameter measured (eosinophil, neutrophils and lymphocytes) (Fig. 1). On day 1 pc, group 2 had significantly elevated PB eosinophils. The upward trend continued on day 3 and 5 pc with significant difference between eosinophils in group 2 compared to group 1 . At the remaining time points, days 7 and $28 \mathrm{pc}$, eosinophils remained elevated above the control group but not significantly. There were no significant differences observed in the other PB leukocytes at any time point.

\subsection{Lymphocyte kinetics into abomasal tissues after challenge}

No difference was observed in total leukocyte $\left(\mathrm{CD} 45^{+}\right.$cells) numbers between groups 1 and 2 before challenge (Fig. 2). Following challenge, group 2 showed an upward trend which reached significance at day 3 before reaching a plateau for the remaining time points.

$\mathrm{CD}^{+}$cells were only slightly and not significantly different between groups 1 and 2 at days 0,1 and 2 pc (Fig. 2). $\mathrm{CD}^{+}$cells were significantly above controls on days 3,7 and $28 \mathrm{pc}$, with a peak at day 3 and a second increase from day 7 to day $28 \mathrm{pc}$. $\mathrm{CD}^{+}$cells were not significantly different at any time point.

$\gamma \delta \mathrm{TCR}^{+}$cells in group 2 increased from day $1 \mathrm{pc}$ and peaked at day $3 \mathrm{pc}$ before decreasing slightly at days 5 and 7 pc (Fig. 2). Like the CD4 T cells, $\gamma \delta$ TCR cells increased again by day $28 \mathrm{pc}$. The $\mathrm{WC} 1 \gamma \delta \mathrm{TCR}\left(\mathrm{T} 19^{+}\right)$cell subset showed a similar trend with two peaks, one occurring at day $3 \mathrm{pc}$ decreasing to the lowest point at day $7 \mathrm{pc}$ before rising again at day $28 \mathrm{pc}$.

CD45 ${ }^{+}$cells which comprise mostly B cells in the abomasum [7] were similar in both groups 1 and 2 over days 0,1 and 2 pc (Fig. 2). At day 3 pc, B cells were significantly higher in group 2 than group 1 and reached a peak at day 5 pc. $\mathrm{CD} 45 \mathrm{R}^{+}$numbers appreciable declined by day 7 , followed by a slight increase in numbers to day 28 .

\subsection{Kinetics of mucosal effector cells after challenge}

Tissue eosinophils, mast cells and globule leukocyte numbers were low in all sheep following the rest period before the challenge (Fig. 3). Group 1 maintained low levels of these cells throughout the post saline challenge. Group 2 showed a significant increase in eosinophils by day 2 pc, reaching a peak at day 3 pc before declining, but remaining above control levels, 

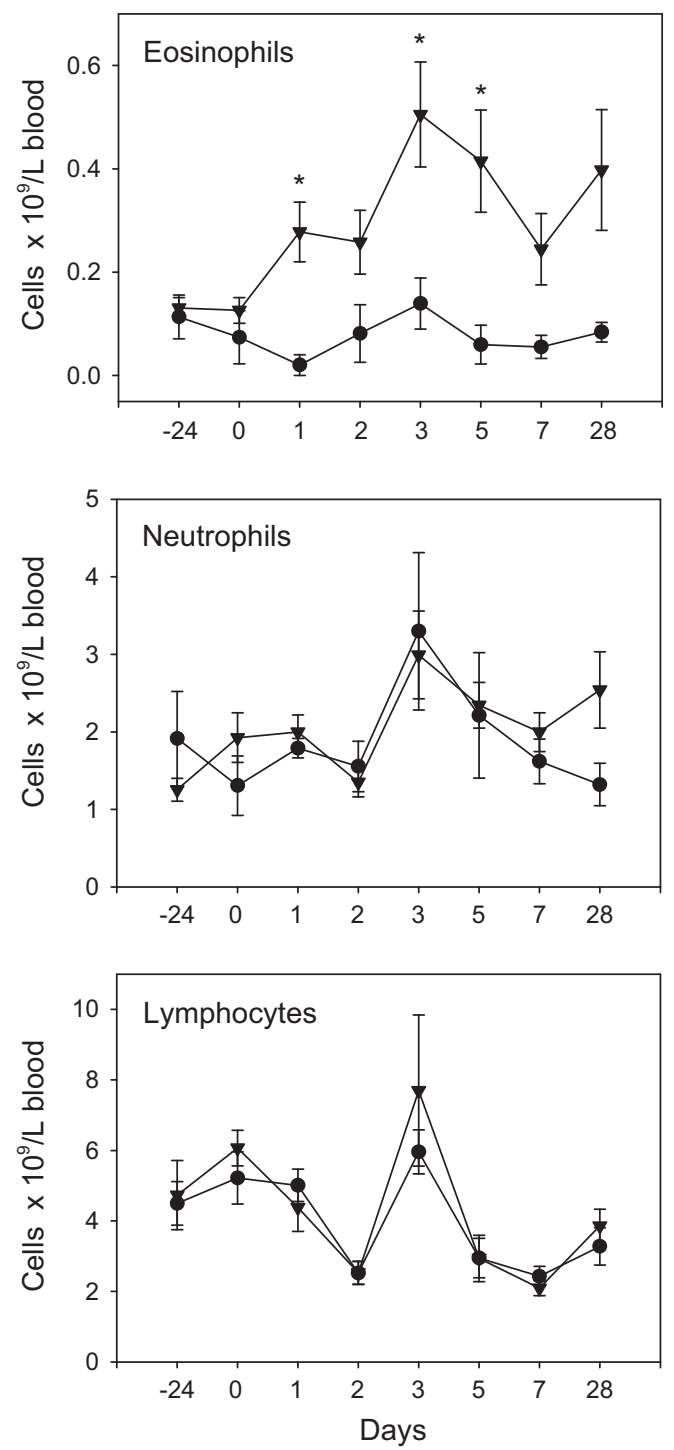

Figure 1. Peripheral blood eosinophils, neutrophils and lymphocytes (mean \pm SEM) in saline challenged $(\boldsymbol{O})$ and L3 challenged $(\boldsymbol{\nabla})$ sensitized sheep, at various days post challenge. ${ }^{*}$ Indicates significant difference $(p<0.05)$.

on days 5 and 7 pc. On day 28 pc eosinophil counts in the L 3 challenge group were again significantly increased above the control group.

Globule leukocytes started to increase on day 2 pc reaching a peak on day 5 pc (Fig. 3). Even though there was a steady decline after day $5 \mathrm{pc}$, globule leukocyte numbers on both days 7 and 28 pc were significantly higher than controls.

Mucosal mast cells showed no change from day 0 to day $4 \mathrm{pc}$, and only started to increase on day 5 pc reaching significance on day 7 and continuing their increase to day 28 pc (Fig. 3). $\mathrm{IgE}^{+}$cells in the L3 challenge group started an 

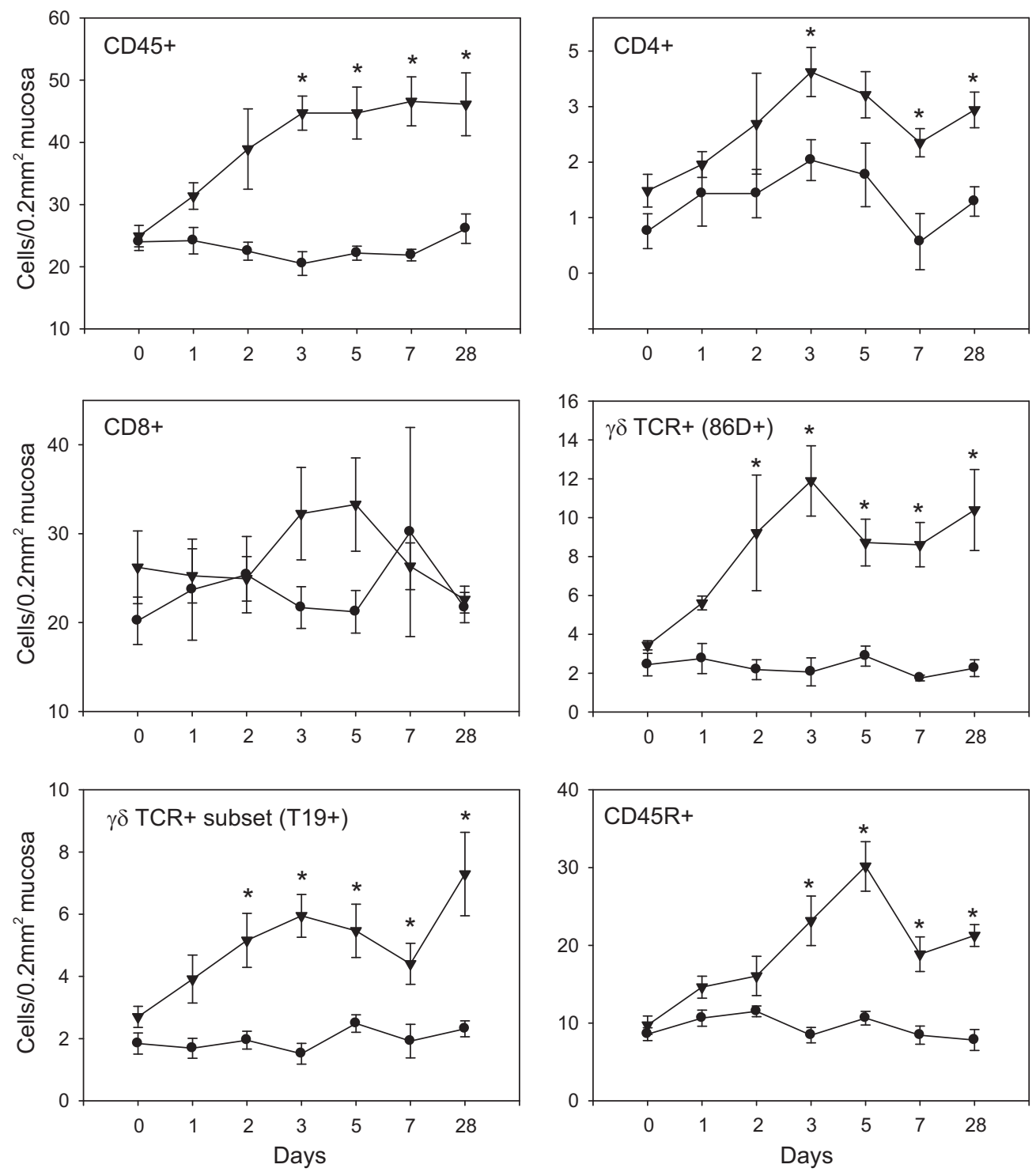

Figure 2. Total leukocytes $\left(\mathrm{CD} 45^{+}\right)$and lymphocyte subsets (means $\pm \mathrm{SEM}$ ) in the abomasal mucosa of saline challenged $(\mathbf{O})$ and L3 challenged $(\boldsymbol{\nabla})$ sensitized sheep, at various days post challenge. ${ }^{*}$ Indicates a significant difference $(p<0.05)$.

upward trend on day $1 \mathrm{pc}$ which did not reach significance until day $5 \mathrm{pc}$ when there was a sharp increase to day $7 \mathrm{pc}$ remaining high at day 28 pc (Fig. 3). While this late increase in $\mathrm{IgE}^{+}$cells somewhat mirrors the late increase in mucosal mast cells, the absolute number of $\mathrm{IgE}^{+}$cells vastly surpassed the mast cell numbers ( $>50$ times on day $7 \mathrm{pc}$ ), suggesting another cell population(s) contributes to the $\operatorname{IgE}^{+}$cell numbers. 

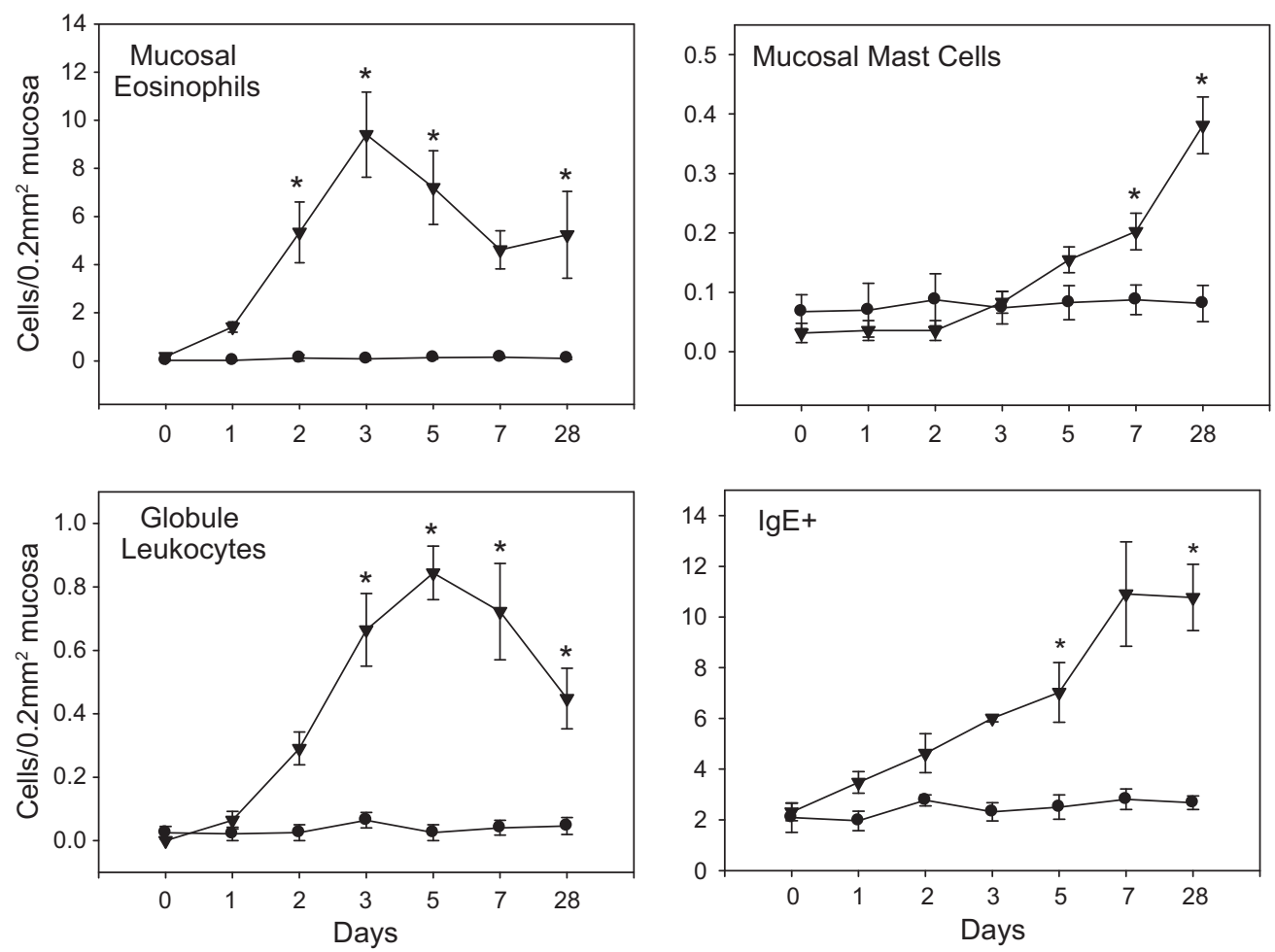

Figure 3. Eosinophils, mast cells, globule leucocytes and $\operatorname{IgE}^{+}$cells (mean $\pm \mathrm{SEM}$ ) in the abomasal mucosa of saline challenged $(\mathbf{O})$ and L3 challenged $(\boldsymbol{\nabla})$ sensitized sheep, at various days post challenge.

* Indicates a significant difference $(p<0.05)$.

\subsection{Adult worm burden}

Adult worm counts measured at day $28 \mathrm{pc}$ showed 3 of the 4 immunized control sheep (group 1) were negative, and one sheep had four adult worms. The sensitized and L3 challenged sheep (group 2) had a small range of adult worm burden, all of which were less than 200 worms per sheep, and the mean was significantly higher than that of group 1 (mean: 67.42; SD: 63.21). Group 3 (naïve challenged) which was used as an infection control group (Tab. I), showed a significantly higher mean $(p<0.05)$ than that of either group 1 or 2 (mean: 850.0; SD: 865).

\subsection{Cellular and parasitological correlations}

The highest negative correlation between worm burden and effector cells was observed with the mucosal eosinophils on day $1 \mathrm{pc}$ $(r=-0.7 ; p=0.08)$.

To assess correlations between cell populations, measurements in the challenged group 2 were averaged over days 2, 3, 5 and $7 \mathrm{pc}$. There was no correlation between MMC and GL but a very strong positive correlation between mucosal eosinophils and GL $(r=0.81 ; p=0.014)$. The only other strong correlation was between $\gamma \delta \mathrm{TCR}^{+}$and $\mathrm{WC}^{+}$cells $(r=0.86$ $p=0.007)$. There was no consistent correlation between peripheral and mucosal eosinophils.

\section{DISCUSSION}

This study provides a detailed examination of cellular recruitment and kinetics of leukocytes following challenge infection of immune sheep. It is clear that an organized and very 
specific immune response has been stimulated in this immune-challenge model which is higher in magnitude and kinetics compared to a primary infection response [2]. The present study differs from previous studies that have investigated the rapid rejection response mediated by a type I hypersensitivity mechanism $[8,15]$. In these studies, sheep were repeatedly infected with large doses of $H$. contortus and T. colubriformis L3 larvae respectively, and resistance to challenge infection was investigated immediately following the sensitization regime. This sensitization and challenge protocol results in rapid rejection and exclusion of challenge larvae from their tissue niche, with little leukocyte infiltration [7]. In contrast, a vigorous immune response was generated in the present study suggesting that larvae are able to penetrate the tissue sufficiently to stimulate the immune system. It is likely that the rest period after sensitization in the present study allowed the rapid exclusion process to wane, as confirmed by the low numbers of globule leukocytes and mast cells at the time of challenge. Sheep were however still protected from the challenge infection as determined by their low worm burden compared to unsensitized control sheep. Previous studies using sequential killing early after challenge were unable to determine the resistance status of the sheep after challenge [3].

The immune response in sensitized sheep was characterized by a rapid rise in both PB and mucosal eosinophil counts in response to larval challenge. Eosinophils have been shown to be able to kill $H$. contortus L3 larvae in vitro [20] and to be intimately associated with damaged L3 in vivo within $24 \mathrm{~h}$ of challenge infection [4]. In the present study, mucosal eosinophils were negatively correlated with worm burden on day 1 , consistent with their role in parasite immunity through killing/damage of infective larvae. Despite the concomitant early rise of blood and tissue eosinophils, strong correlations between these two related cell populations was only apparent on $3 / 7$ days examined and not significant considering the number of samples analysed. Previous studies have also observed unpredictable correlations between PB eosinophils and abomasal tissue eosinophils after GIN infection, both directly and when the correlation is subjected to temporal off-setting $[10,22]$. This lack of correlation may explain the conflicting data regarding eosinophils' role in resistance when only blood eosinophils or single time points are examined.

In the present study, significant increases in globule leukocytes and mast cells were not evident until 3 to 7 days pc respectively. Considering the L3 moults into an L4 within 1-2 days post infection [1], it is unlikely that these cell populations are involved in the rejection of incoming larvae in this infection model. However, it should be recognised that cell number does not necessarily reflect cell function or activity. Globule leukocytes are considered to be derived from mucosal mast cells that migrate into the epithelial compartment [11]. It was therefore surprising that no positive correlations were found between these 2 cell populations. However, a strong positive correlation was found between globule leukocytes and mucosal eosinophils. This may indicate that the generation of globule leukocytes is dependent on the same stimuli as eosinophils or on eosinophilderived factors.

CD4 T cells have been shown to be important in both primary or challenge infection with $H$. contortus $[6,16,17,19]$ and a significant biphasic $\mathrm{CD}^{+}$response after challenge infection of immune sheep was also observed in the present study. The first peak at day 3 indicates a memory response which is most likely stimulated by the presence of $H$. contortus L3 larvae entering the abomasal crypts following challenge, which was also seen in a previous post-mortem study [3]. CD4 T cell numbers in the present study appeared to wane following this initial peak before increasing again when an adult $H$. contortus infection has established. These results are in agreement with previous studies that have shown immunological responses of both humoral and cellular origin which peak at the time of presence of T. colubriformis L3 larval and adult stages in the small intestine $[18,23]$.

A clear biphasic response was also observed with the $\gamma \delta \mathrm{TCR}^{+}$cells and the $\mathrm{WCl}(\mathrm{T} 19)^{+}$subpopulation, indicating that these cells are also most likely responding differentially to larval 
and adult $H$. contortus antigens. Interestingly, although CD4 $\mathrm{T}$ cells are generally thought to be responsible for eosinophilia through the production of interleukin (IL)-5, both the $\gamma \delta \mathrm{TCR}^{+}$ populations and mucosal eosinophils increased earlier by day $1 \mathrm{pc}$, at a time larval damage is evident [4]. It is possible that $\gamma \delta$ T cells may recruit eosinophils early in larval infection, before the increase in CD4 $\mathrm{T}$ cells. The involvement of $\mathrm{WC1}^{+} \gamma \delta$ T cells in eosinophil recruitment is supported by previous studies that showed that most WC1 (T19) ${ }^{+}$cells present in the mucosa of sheep infected with $T$. colubriformis were strongly positive for IL-5 [5].

Similar to the CD4 and $\gamma \delta$ T cells, the B cell $\left(\mathrm{CD} 45 \mathrm{R}^{+}\right)$response also follows a biphasic pattern indicative of a memory response against both larval and adult antigens. In contrast, total leukocyte numbers remained elevated and the $\mathrm{IgE}^{+}$cell population continued to increase between days 5 and 28. Mucosal mast cells are known to be $\operatorname{IgE} \mathrm{E}^{+}$, but their number is too small to account for the increase in $\operatorname{IgE}^{+}$cells and total leukocytes. IgE producing B cells and plasma cells have been previously observed in tissues after infection with gastrointestinal nematodes [19] and B cells are known to lose surface antigens (including CD45R) upon differentiation [13]. It is therefore likely that the large increase in $\mathrm{IgE}^{+}$cells at days $5-28 \mathrm{pc}$, and the elevated CD $45^{+}$numbers on day 7 are due to differentiation of $\mathrm{B}$ cells into $\mathrm{IgE}^{+}$plasma cells.

In contrast to previous studies showing immune exclusion of challenge larvae in hypersensitized sheep, a period of parasite free time was introduced in the present experiment before the final larval challenge. This rest period, which can be compared to the non-infective period on pasture, allowed the globule leukocyte/mast cell-mediated hypersensitivity mechanism to regress and an eosinophil dominated mechanism to operate. The results of this study highlights the need for careful consideration of the sensitization protocols used, as different mechanisms of immunity may be operating against the same parasite, as suggested previously [1]. The present study also significantly extends the work done by Balic et al. [3] by using sequential time points in the same animal to investigate resistant sheep following a larval challenge. This allowed very early time points to be studied while still being able to relate the findings to resistance readouts such as total adult worm count. In addition, meaningful correlations between cell populations within the same animal could be derived, providing a more complete picture of cellular interactions at both peripheral and local sites, and their correlation with the different stages of parasite development.

\section{REFERENCES}

[1] Balic A., Bowles V.M., Meeusen E.N., The immunobiology of gastrointestinal nematode infections in ruminants, Adv. Parasitol. (2000) 45:181-241.

[2] Balic A., Bowles V.M., Meeusen E.N.T., Cellular profiles in the abomasal mucosa and lymph node during primary infection with Haemonchus contortus in sheep, Vet. Immunol. Immunopathol. (2000) 75:109-120.

[3] Balic A., Bowles V.M., Meeusen E.N.T., Mechanisms of immunity to Haemonchus contortus infection in sheep, Parasite Immunol. (2002) 24:39-46.

[4] Balic A., Cunningham C.P., Meeusen E.N., Eosinophil interactions with Haemonchus contortus larvae in the ovine gastrointestinal tract, Parasite Immunol. (2006) 28:107-115.

[5] Bao S., McClure S.J., Emery D.L., Husband A.J., Interleukin-5 mRNA expressed by eosinophils and gamma/delta T cells in parasite-immune sheep, Eur. J. Immunol. (1996) 26:552-556.

[6] Gill H.S., Watson D.L., Brandon M.R., Monoclonal antibody to $\mathrm{CD} 4+\mathrm{T}$ cells abrogates genetic resistance to Haemonchus contortus in sheep, Immunology (1993) 78:43-49.

[7] Gorrell M.D., Miller H.R., Brandon M.R., Lymphocyte phenotypes in the abomasal mucosa of sheep infected with Haemonchus contortus, Parasite Immunol. (1988) 10:661-674.

[8] Harrison G.B., Pulford H.D., Gatehouse T.K., Shaw R.J., Pfeffer A., Shoemaker C.B., Studies on the role of mucus and mucosal hypersensitivity reactions during rejection of Trichostrongylus colubriformis from the intestine of immune sheep using an experimental challenge model, Int. J. Parasitol. (1999) 29: 459-468.

[9] Hayes K.S., Bancroft A.J., Grencis R.K., Immune-mediated regulation of chronic intestinal nematode infection, Immunol. Rev. (2004) 201:75-88.

[10] Henderson N.G., Stear M.J., Eosinophil and IgA responses in sheep infected with Teladorsagia 
circumcincta, Vet. Immunol. Immunopathol. (2006) 112:62-66.

[11] Huntley J.F., Newlands G., Miller H.R.P., The isolation and characterization of globule leucocytes: their derivation from mucosal mast cells in parasitized sheep, Parasite Immunol. (1984) 6:371-390.

[12] Huntley J.F., Jackson F., Coop R.L., Macaldowie C., Houdijk J.G., Familton A.S., et al., The sequential analysis of local inflammatory cells during abomasal nematode infection in periparturient sheep, Vet. Immunol. Immunopathol. (2004) 97: 163-176.

[13] Jensen G.S., Poppema S., Mant M.J., Pilarski L.M., Transition in CD45 isoform expression during differentiation of normal and abnormal B cells, Int. Immunol. (1989) 1:229-236.

[14] McClure S.J., Emery D.L., Wagland B.M., Jones W.O., A serial study of rejection of Trichostrongylus colubriformis by immune sheep, Int. J. Parasitol. (1992) 22:227-234.

[15] Miller H.R., Jackson F., Newlands G., Appleyard W.T., Immune exclusion, a mechanism of protection against the ovine nematode Haemonchus contortus, Res. Vet. Sci. (1983) 35:357-363.

[16] Miller J.E., Horohov D.W., Immunological aspects of nematode parasite control in sheep, J. Anim. Sci. (2006) 84(Suppl.):E124-E132.

[17] Pena M.T., Miller J.E., Horohov D.W., Effect of CD4(+) T lymphocyte depletion on resistance of Gulf Coast Native lambs to Haemonchus contortus infection, Vet. Parasitol. (2006) 138:240-246.
[18] Pernthaner A., Cabaj W., Shaw R.J., Rabel B., Shirer C.L., Stankiewicz M., Douch P.G.C., The immune response of sheep surgically modified with intestinal loops to challenge with Trichostrongylus colubriformis, Int. J. Parasitol. (1996) 26:415-422.

[19] Pfeffer A., Douch P.G.C., Shaw R.J., Gatehouse T.K., Rabel B., Green R.S., et al., Sequential cellular and humoral responses in the abomasal mucosa and blood of Romney sheep dosed with Trichostrongylus axei, Int. J. Parasitol. (1996) 26:765-773.

[20] Rainbird M.A., MacMillan D., Meeusen E.N.T., Eosinophil-mediated killing of Haemonchus contortus larvae: effect of eosinophil activation and role of antibody, complement and interleukin-5, Parasite Immunol. (1998) 20:93-103.

[21] Scott I., Khalaf S., Simcock D.C., Knight C.G., Reynolds G.W., Pomroy W.E., Simpson H.V., A sequential study of the pathology associated with the infection of sheep with adult and larval Ostertagia circumcincta, Vet. Parasitol. (2000) 89:79-94.

[22] Stear M.J., Bishop S.C., Duncan J.L., McKellar Q.A., Murray M., The repeatability of faecal egg counts, peripheral eosinophil counts, and plasma pepsinogen concentrations during deliberate infections with Ostertagia circumcincta, Int. J. Parasitol. (1995) 25:375-380.

[23] Sutherland I.A., Leathwick D.M., Green R., Brown A.E., Miller C.M., The effect of continuous drug exposure on the immune response to Trichostrongylus colubriformis in sheep, Vet. Parasitol. (1999) 80:261-271. 